\title{
ANÁLISE SOBRE TEMÁTICAS DE EDUCAÇÃO ESPECIAL E INCLUSIVA NO PROGRAMA DE EDUCAÇÃO ESCOLAR DA FCL/CAr
}

\author{
ANALISIS SOBRE TEMÁTICAS DE EDUCACIÓN ESPECIAL E INCLUSIVA EM \\ EL PROGRAMA DE EDUCACIÓN ESCOLAR DE LA FCL/CAr
}

\section{ANALYSIS ON THE THEME OF SPECIAL AND INCLUSIVE EDUCATION IN THE SCHOOL EDUCATION PROGRAM AT FCL/CAr}

\author{
Relma Urel Carbone CARNEIRO ${ }^{1}$ \\ Maria Júlia Canazza DALL'ACQUA ${ }^{2}$ \\ Patricia Moralis CARAMORI ${ }^{3}$ \\ Daniel Bianconi PREVIATO ${ }^{4}$
}

RESUMO: O presente estudo tem como objetivo continuar uma investigação anterior sobre levantamento da produção do Programa de Pós-graduação em Educação Escolar da Universidade Estadual Paulista no que diz respeito às temáticas da Educação Especial e Inclusiva. Para verificar a tendência atual e, posteriormente, realizar um paralelo entre os dois períodos investigados, foi replicado o mesmo procedimento, cujo objetivo é caracterizar a produção científica. No período analisado, de outubro/2008 a março/2015, foram localizadas 24 produções pertinentes. A análise foi qualiquantitativa. Os resultados demonstram que os trabalhos totalizaram 7,57\% em média da produção, o que pode ser considerado pouco. A temática mais investigada foi Inclusão Escolar e o lócus preferencial foi a Escola, mostrando que o eixo de interesses tem características abrangentes e contextualizadas. Alinhada com a pesquisa nacional, a produção tem contemplado temáticas emergentes e relevantes, sinalizando na direção dos professores e também dos alunos público alvo da Educação Especial.

PALAVRAS-CHAVE: Educação Especial. Educação Inclusiva. Produção científica.

RESUMEN: El presente estudio tiene como objetivo continuar una investigación anterior sobre búsqueda de la producción del Programa de Posgrado en Educación Escolar de la Universidad Estadual Paulista en el que dice respeto a las temáticas de la Educación Especial e Inclusiva. Para verificar la tendencia actual y, posteriormente, realizar una comparación entre los dos períodos investigados, fue replicado el mismo procedimiento, cuyo objetivo es caracterizar la producción científica. En el período

\footnotetext{
${ }^{1}$ Faculdade de Ciências e Letras da Universidade Estadual Paulista (FCLAr/UNESP), Araraquara - SP Brasil. Professora Assistente Doutora do Departamento de Psicologia da Educação. E-mail: relmaurel@fclar.unesp.br

${ }^{2}$ Faculdade de Ciências e Letras da Universidade Estadual Paulista (FCLAr/UNESP) Araraquara - SP Brasil. Professora Doutora aposentada do Departamento de Psicologia da Educação. E-mail: juliacandal@gmail.com

${ }^{3}$ Universidade Federal de São Carlos (UFSCar), São Carlos - SP, Brasil. Pós-doutoranda em Educação Especial pelo Programa de Pós-graduação em Educação Especial. E-mail: p.caramori@uol.com.br

${ }^{4}$ Universidade Federal de São Carlos (UFSCar), São Carlos - SP - Brasil. Doutorando em Educação pelo Programa de Pós-graduação em Educação - PPGE. E-mail: danielpreviato@ yahoo.com.br
} 
analizado, de octubre/2008 a marzo/2015, fueron localizadas 24 producciones pertinentes. El análisis fue cuali-cuantitativo. Los resultados demuestran que los trabajos totalizaron 7,57\% de promedio de la producción, el que puede ser considerado poco. La temática más investigada fue Inclusión Escolar y el locus preferencial fue la Escuela, muestreando que el eje de interés tiene características incluyentes y contextualizadas. Alineada con la investigación nacional, la producción hay contemplado temáticas emergentes y relevantes, señalando hacia los profesores y también los alumnos público blanco de la Educación Especial.

PALABRAS CLAVE: Educación Especial. Educación Inclusiva. Producción científica.

ABSTRACT: The present study was carried out with the objective to continue an investigation undertaken previously, when a first survey of the production of the Postgraduate Program in School Education of the State University of São Paulo was given with regard to the themes of Special and Inclusive Education. To verify the current tendency to later carry out a parallel between the two investigated periods, the same procedure was then replicated, whose objective was to characterize the scientific production. In the period analyzed, from October / 2008 to March / 2015, 24 relevant productions were located. The analysis was qualitative-quantitative. Results showed that the works totaled $7,57 \%$ on the average the production, which can still be considered little. The most investigated theme was School Inclusion and the preferred locus was the school, showing that the interest axis has comprehensive and contextualized characteristics. Aligned with national research, the production has contemplated emerging and relevant themes, signaling towards the teachers, as well as the students who are the target audience of special education.

KEYWORDS: Special Education. Inclusive Education. Scientific production.

\section{Introdução}

O conhecimento é um elemento diferenciador entre o ser humano e as outras espécies. Porque conhecemos e temos consciência de que conhecemos somos capazes de agir de forma planejada, modificando a realidade. Essa possibilidade de modificação do que está dado demonstra que o conhecimento que temos é sempre parcial e passível de revisões, alterações, inclusões e transformações. Desta forma somos capazes de produzir conhecimento sempre que em contato com o real e agimos no sentido de modificá-lo. Esse conhecimento, visto em sua generalidade, pode ser esquadrinhado a partir de um mecanismo formal de organização capaz de sistematizar dados de áreas, níveis, enfim, subsidiar a evolução social. A pesquisa científica é um mecanismo de sistematização e organização de dados que objetiva a constatação, a produção e a disseminação do conhecimento em suas mais variadas formas, em uma dada sociedade. 
Em Educação a pesquisa e, consequentemente, a produção de conhecimento, tem características muito particulares, uma vez que a realidade sobre a qual atua é composta de complexos processos de desenvolvimento e aprendizagens humanos, elementos pouco previsíveis e nada determinados. No entanto, neste campo da Educação, o conhecimento é cada vez mais valioso, justamente pela complexidade de sua atuação. Em nosso modelo social, em que a Educação acontece em grande medida na instituição escolar, responsável por transmitir o conhecimento existente, a pesquisa sobre como esses processos ocorrem e sobre a eficácia de sua abrangência são extremamente relevantes.

A Educação Especial, que em nosso sistema educacional é responsável pela garantia de acompanhamento especializado a alunos com deficiências, transtornos globais de desenvolvimento ou altas habilidades/superdotação, que na maioria das vezes em função de características específicas requerem ações, recursos, estratégias de ensino diferentes das comumente disponíveis, constitui um vasto campo de pesquisa com importantes contribuições para a produção do conhecimento humano.

A pesquisa em Educação Especial é uma prática relativamente nova no Brasil, com menos de quarenta anos de existência. Ela coincide com a necessidade de formação para professores especializados que atuariam com alunos com deficiência, neste momento, em sua maioria, alunos de escolas e classes especiais. Como uma iniciativa inovadora a Universidade Federal de São Carlos (UFSCar) criou, em 1978, o primeiro Programa de Pós-graduação, inicialmente com o Mestrado, que tinha como foco a Educação Especial, com o intuito de formar profissionais para a área. De lá para cá, embora o Programa de Pós-graduação da UFSCar continue sendo o único do Brasil em Educação Especial, muitos outros oferecem linhas de pesquisa específicas na área ou outras linhas mais abrangentes que englobam temas deste campo de conhecimento. A partir de então, a investigação dos mais variados aspectos que envolvem a Educação Especial vem se consolidando em nosso País, acompanhando a evolução desta temática em suas diferentes nuances.

A análise desta produção científica contribui de forma expressiva para o entendimento dos rumos que a área vem tomando, bem como, para uma reflexão crítica de sua própria pesquisa, contribuindo assim para o seu amadurecimento enquanto campo de conhecimento. Bueno (2014) ressalta que: 
[...] a produção oriunda de mestrandos e doutorandos dos programas de pós-graduação pode ser considerada como expressão qualificada dos caminhos que a pesquisa em educação especial tem percorrido, se não nos ativermos a elas como expressões individuais, mas como resultado do trabalho coletivo desenvolvido nos mais diferentes programas, envolvendo suas linhas, grupos e projetos de pesquisa. (BUENO, 2014, p. 214)

Vários autores renomados já empreenderam esta tarefa de análise, como Nunes, Ferreira e Mendes (2004); Bueno (2004; 2007; 2014); Manzini (2006); Dall'Acqua e Zaniolo (2009); Ferreira e Bueno (2011), entre outros. Esses estudos demonstram a análise de diferentes aspectos investigados, como população pesquisada, locais de pesquisa, abordagens metodológicas, procedimentos metodológicos, fundamentação teórica, área de conhecimento, periodicidade da produção, entre outros, demonstrando um expressivo avanço nas pesquisas da área e eventuais lacunas a serem observadas.

Em trabalho recente, Bueno (2014) apresenta um levantamento feito a partir do acervo do banco de dissertações e teses disponibilizado pela Coordenação de Aperfeiçoamento de Pessoal de Nível Superior (Capes) compreendendo o período 1987 a 2010 e 1.068 trabalhos que foram analisados, com o intuito de responder a três questões específicas, a saber: quem e quando investigaram, sobre o que investigaram, com que e como lidaram com o tema. Seus dados mostram que a investigação em Educação Especial no Brasil se dá majoritariamente em instituições públicas, com pouquíssimas instituições privadas como coadjuvantes. Existe uma concentração desta produção em alguns poucos Programas com grande tradição na área que reúnem um conjunto reconhecido de pesquisadores/orientadores e uma grande dispersão de orientadores responsáveis por uma ou duas produções cada. Como área de conhecimento em que se situam essas produções temos a Educação com praticamente $80 \%$ de toda a produção e a Psicologia e Saúde-Reabilitação como principais áreas, sendo que poucos trabalhos, 95 do total, eram de outras áreas. A imprecisão da terminologia que designa o público alvo da Educação Especial e suas constantes variações em decorrência de políticas públicas e legislação contribuem para uma ambiguidade da pesquisa, sendo, conforme o autor, necessário maior rigor e precisão. $\mathrm{O}$ autor apresenta ainda, como dados de sua análise, a alta incidência da produção de um conhecimento prático, que embora favoreça o atendimento das necessidades dos sujeitos objeto deste campo de conhecimento, pouco contribui para o avanço do conhecimento teórico, limitando as possibilidades de atuação que acabam tendo como base exclusiva 
as características intrínsecas dessa população e não a relação dessas características com as condições sociais.

Seguindo essa linha de raciocínio e buscando analisar a produção também no Programa de Pós-graduação em Educação Escolar da Faculdade de Ciências e Letras da Universidade Estadual Paulista "Júlio de Mesquita Filho" (Unesp), Campus de Araraquara (FCL/CAr) acerca das pesquisas na área da Educação Especial dentro de suas linhas de pesquisa, Dall'Acqua e Zaniolo (2009) fizeram um mapeamento e uma análise dessa produção no período de 2002 a 2008, com o objetivo de apresentar as tendências deste tipo de investigação neste Programa. Transcorridos quase 10 anos dessa primeira investigação, quais as características da produção mantiveram-se as mesmas ou alteraram-se ao longo do tempo no período seguinte? Será relevante enfocar e construir uma compreensão acerca dos rumos da produção em um Programa de Pósgraduação, por meio do afunilamento do foco na continuidade de uma temática ao longo de 14 anos?

Sob essa perspectiva, a pesquisa relatada no presente artigo emergiu, e foi motivada, pelas discussões dos grupos de pesquisa Educação Especial: Contextos de Formação e Práticas Pedagógicas e Grupo de Estudos e Pesquisas sobre Educação Especial e Inclusiva (GEPEEI) da FCL/CA, tendo como objetivo dar continuidade ao levantamento e apreciações já mencionados para, dessa forma, analisar a produção deste mesmo Programa a partir do que foi produzido desde então, visando um novo mapeamento, análise e considerações sobre o conhecimento sendo produzido.

\section{Método}

O levantamento da produção científica do Programa de Pós-graduação em Educação Escolar acerca do tema Educação Especial e Inclusiva permite conhecer de que maneira, e sob quais perspectivas, nesse âmbito o assunto vem sendo tratado.

Para se fazer o referido levantamento, primeiramente, foram selecionados todos os trabalhos defendidos no Programa no período de outubro de 2008 a março de 2015. Foram lidos todos os títulos e palavras-chave em busca de termos que fizessem referência à área da Educação Especial e Inclusiva ou à Educação de alunos público alvo da Educação Especial.

A partir dessa busca realizada com o referido filtro, 24 trabalhos foram classificados como pertencentes à área da Educação Especial e Inclusiva. Somente os 
resumos dos 24 trabalhos foram lidos e analisados. Nestes textos buscaram-se informações pertencentes a cada uma das categorias estabelecidas para posterior apreciação.

A análise foi realizada tanto de forma qualitativa como quantitativa, pois acredita-se que, dessa forma seria possível construir um panorama mais abrangente acerca das produções do Programa de Pós-graduação. Sobre os métodos de pesquisa qualitativos, Gatti e André (2013) fazem a seguinte afirmação, que vem contribuir com a perspectiva do presente estudo:

A aplicabilidade dos conhecimentos na área da educação depende do desenvolvimento de compreensões apropriadas, o que depende das condições de rigor nos cuidados investigativos, o que não quer dizer seguimento de rígidos protocolos, mas, sim, de domínio flexível de métodos e instrumentais necessários à aproximação significativa do real. (GATTI; ANDRÉ, 2013, p. 37)

Dessa forma, a escolha do método de pesquisa e análise vem ao encontro do que se espera como resultado do presente estudo, no sentido de contribuir com o cenário da Educação Especial e Inclusiva, mapeando o que vem sendo realizado na área, bem como apontando possíveis novos indicadores de temáticas e abordagens ainda necessárias de serem estudadas.

\section{Resultados e Discussão}

Os resultados obtidos mostram que no período compreendido entre outubro de 2008 e março de 2015 foram defendidas 173 dissertações e 150 teses, totalizando 323 trabalhos, sendo que, desse conjunto, aqueles identificados com temáticas relativas à Educação Especial e Inclusiva, foco dessa investigação, são também apresentados e detalhados no quadro que se segue.

Quadro 1: Total de defesas de Mestrado e Doutorado e fração na temática em Educação Especial e Inclusiva realizadas no Programa de Pós-graduação em Educação Escolar no período de 2008 a 2015. 
Quadro 1: Amostragem das defesas do PPG

\begin{tabular}{|c|c|c|c|c|c|c|c|}
\hline \multirow{2}{*}{ Ano } & \multicolumn{6}{|c|}{ Defesas no Programa de Pós-graduação em Educação Especial } \\
\cline { 2 - 8 } & Mestrado & Doutorado & $\begin{array}{c}\text { Total de } \\
\text { defesas }\end{array}$ & Mestrado & Doutorado & $\begin{array}{c}\text { Total de } \\
\text { defesas }\end{array}$ & $\begin{array}{c}\text { Porcenta- } \\
\text { gens (\%) }\end{array}$ \\
\hline 2008 & 2 & 2 & 4 & - & - & - & - \\
\hline 2009 & 40 & 22 & 62 & 6 & - & 6 & 9,6 \\
\hline 2010 & 28 & 23 & 51 & 2 & 1 & 3 & 5,8 \\
\hline 2011 & 18 & 33 & 51 & 1 & 1 & 2 & 3,9 \\
\hline 2012 & 4 & 27 & 31 & 1 & 2 & 3 & 9,7 \\
\hline 2013 & 17 & 13 & 30 & 1 & - & 1 & 3,3 \\
\hline 2014 & 42 & 27 & 69 & 2 & 4 & 6 & 8,7 \\
\hline 2015 & 22 & 3 & 25 & 3 & - & 3 & 12,0 \\
\hline Total & $\mathbf{1 7 3}$ & $\mathbf{1 5 0}$ & $\mathbf{3 2 3}$ & $\mathbf{1 6}$ & $\mathbf{8}$ & $\mathbf{2 4}$ & $\mathbf{( \mathbf { 9 , 2 } \% )}$ \\
\hline
\end{tabular}

Fonte: Elaboração própria

O quadro apresentado mostra o número de trabalhos defendidos no Programa no período de outubro de 2008 a março de 2015. Não foram encontrados trabalhos referentes à área de Educação Especial em nível de mestrado e doutorado no ano de 2008 e de doutorado nos anos de 2009, 2013 e 2015.

Optou-se por apresentar somente a porcentagem total dos trabalhos por ano, pois esses dados mostraram-se mais consistentes. Assim sendo, apesar de haver apenas 23 trabalhos de mestrado a mais do que de doutorado, no total, 173 para 150 respectivamente, as pesquisas voltadas para temáticas pertinentes à Educação Especial e Inclusiva, de forma geral, no mestrado somam 16 pesquisas concluídas e defendidas, o dobro do número de trabalhos em nível de doutorado, que foi de apenas oito.

Em relação à porcentagem, os 16 trabalhos de mestrado representam 9,2\% do total de defesas desse nível da pós-graduação. Já os oito trabalhos de doutorado representam 5,3\% da produção. Dessa forma, no período de seis anos e seis meses levantados, os trabalhos relativos à Educação Especial totalizaram 24 defesas, caracterizando $5,4 \%$ da produção.

Vale destacar que na organização do conjunto das cinco linhas de pesquisa que compõem o Programa de Pós-graduação em Educação Escolar, atualmente a área da Educação Especial apresenta-se integrada às diferentes linhas, embora não tenha sido sempre assim. Até o ano de 2010 havia especificamente uma linha de pesquisa intitulada Trabalho Educativo: Fundamentos Psicológicos e Educação Especial que, no entanto, foi extinta, permanecendo uma reorganização de forma a contemplar 
investigações em sexualidade, formação de professores e práticas pedagógicas, teorias pedagógicas e trabalho educativo, estudos históricos e, por fim, política educacional. Esse movimento acabou por resultar na possibilidade de presença de temáticas da Educação Especial em qualquer uma das linhas citadas.

A partir da identificação de palavras-chave presentes com maior recorrência nos resumos das dissertações e teses, foi possível organizar o Quadro 2 que se segue. Cabe mencionar que, por haver palavras comuns a mais de um trabalho, as porcentagens foram calculadas em relação ao número total de trabalhos.

Quadro 2: Relação de palavras-chave com maior recorrência nas dissertações e teses sobre a temática da Educação Especial, por ordem de ocorrência e porcentagens

\begin{tabular}{|l|c|c|}
\hline \multicolumn{1}{|c|}{ Palavras-chave } & $\begin{array}{c}\text { Número de } \\
\text { ocorrências }\end{array}$ & $\begin{array}{c}\text { Porcentagens } \\
\text { (\%) }\end{array}$ \\
\hline Inclusão escolar & 10 & 41,66 \\
\hline Educação especial & 9 & 37,50 \\
\hline Educação inclusiva & 4 & 16,66 \\
\hline Inclusão & 4 & 16,66 \\
\hline Surdez & 4 & 16,66 \\
\hline Formação de professores & 4 & 16,66 \\
\hline Educação & 2 & 8,33 \\
\hline Escrita & 2 & 8,33 \\
\hline LIBRAS & 2 & 8,33 \\
\hline Educação fisica & 2 & 8,33 \\
\hline Formação continuada & 2 & 8,33 \\
\hline Experiência de aprendizagem mediada & 2 & 8,33 \\
\hline Prática docente & 2 & 8,33 \\
\hline Deficiência intelectual & 2 & 8,33 \\
\hline
\end{tabular}

Fonte: Elaboração própria

A leitura das informações contidas no Quadro 2 permite constatar que os dois termos mais citados nos trabalhos correspondem à caracterização de uma grande área de conhecimento, em razão da presença de Inclusão Escolar e Educação Especial como as 19 referências mais frequentes. É interessante salientar, no entanto, que a palavra Educação Especial foi localizada juntamente com Inclusão Escolar em três dos trabalhos, enquanto que em outros dois foi associada à Educação Inclusiva que, por sua vez, teve isoladamente um número menor de ocorrências, totalizando quatro delas. No entanto, tal configuração mostra que no período em questão o foco principal de 
investigação nas dissertações e teses versou sobre a questão da Inclusão Escolar, aspecto que confirma uma tendência crescente que já se anunciava na produção discente do Programa de Pós-graduação em Educação Escolar, com aumento progressivo de pesquisas tratando da Inclusão Escolar como sua questão central (DALL'ACQUA; ZANIOLO, 2009).

O conjunto das demais palavras-chave, a maior parte delas com duas ocorrências, evidenciou uma gama diversificada de temáticas, mas que, ainda assim, tiveram em comum o destaque para a questão da escola e seus professores, seja no que diz respeito à formação como também à prática.

No que se refere às demais palavras-chave, 59 delas no total, por configurarem um único registro, as mesmas foram agrupadas por temas, como é possível conferir no quadro apresentado a seguir.

Quadro 3: Relação de Palavras-chave, de registro único, agrupadas por tema

\begin{tabular}{|c|c|}
\hline Palavras-chave & Temas \\
\hline $\begin{array}{l}\text { - Educação de jovens e adultos } \\
\text { - Educação física adaptada } \\
\text { - Educação escolar } \\
\text { - Educação a distância } \\
\text { - Educação infantil } \\
\text { - Educação infantil inclusiva } \\
\text { - Ensino fundamental } \\
\text { - Escola } \\
\text { - Educação superior }\end{array}$ & MODALIDADES DE ENSINO \\
\hline $\begin{array}{l}\text { - Deficiência } \\
\text { - Deficiência mental severa } \\
\text { - Pessoa com deficiência visual } \\
\text { - Intérprete de Libras } \\
\text { - Implante coclear } \\
\text { - Educação para surdos } \\
\text { - Educação de surdos } \\
\text { - Deficiência visual }\end{array}$ & DEFICIÊNCIAS \\
\hline $\begin{array}{l}\text { - Pedagogia Institucional } \\
\text { - ReuwenEeuerstein } \\
\text { - Perspectiva bioecclógica } \\
\text { - Abordagem Histórico-cultural } \\
\text { - Psicanálise } \\
\text { - Narrativas (auto)biográficas } \\
\text { - Estudo comparativo } \\
\text { - Consultoria colaborativa } \\
\text { - Colaboração } \\
\text { - Discurso }\end{array}$ & $\begin{array}{c}\text { REFERENCIAIS TEÓRICOS E } \\
\text { METODOLOGIAS }\end{array}$ \\
\hline
\end{tabular}




\begin{tabular}{|c|c|}
\hline $\begin{array}{l}\text { - Salas de recursos multifuncionais } \\
\text { - Sala de recursos } \\
\text { - Atendimento educacional especializado } \\
\text { - Aprendizagem-desenvolvimento } \\
\text { - Material didático } \\
\text { - Currículo do Estado de São Paulo } \\
\text { - Adaptação curricular } \\
\text { - Política Educacional } \\
\text { - Censo Escolar } \\
\text { - Matrículas } \\
\text { - Instrumentos formativos } \\
\text { - Grupo }\end{array}$ & ESCOLA \\
\hline $\begin{array}{l}\text { - Prática docente em educação especial } \\
\text { - Prática pedagógica } \\
\text { - Atuação docente } \\
\text { - Professores } \\
\text { - Formação docente } \\
\text { - Estratégias pedagógicas } \\
\text { - Processo de ensino-aprendizagem } \\
\text { - Atuação de profissionais }\end{array}$ & ATUAÇÃO DE PROFESSORES \\
\hline $\begin{array}{l}\text { - Alunos do ensino médio } \\
\text { - Trajetória escolar } \\
\text { - Sujeito }\end{array}$ & ALUNO \\
\hline $\begin{array}{l}\text { - Tecnologia Assistiva } \\
\text { - Acessibilidade }\end{array}$ & TECNOLOGIA \\
\hline $\begin{array}{l}\text { - Produção acadêmica } \\
\text { - Campo do conhecimento } \\
\text { - Tendências temáticas } \\
\text { - Pós-Graduação }\end{array}$ & $\begin{array}{l}\text { PRODUÇÃO DE } \\
\text { CONHECIMENTO }\end{array}$ \\
\hline $\begin{array}{l}\text { - Mãe } \\
\text { - Relação família-escola }\end{array}$ & FAMÍLIA \\
\hline - Mercado de Trabalho & $\begin{array}{l}\text { TRABALHO DE PESSOAS COM } \\
\text { DEFICIÊNCLA }\end{array}$ \\
\hline
\end{tabular}

Fonte: Elaboração própria

Os dados apresentados no Quadro 3 evidenciam a relação de termos unitários extraídos das dissertações e teses como objeto de análise, permitindo reconhecer o universo de assuntos abordados nos trabalhos defendidos. Estabelecendo coerência com o perfil do Programa de Pós-graduação em Educação Escolar, é possível notar que o conjunto majoritário de termos unitários foi agrupado na categoria temática denominada "Escola". Há que se destacar, porém, que a maioria das palavras-chave se enquadrou nas "Modalidades de ensino", nos "Referenciais teóricos e metodologias" e, ainda, na "Atuação de professores", restando aos demais uma representatividade menos frequente. Analisando mais detalhadamente cada um desses temas é possível verificar que no que diz respeito às "Modalidades de ensino", houve uma diversidade de interesses, incluindo até mesmo aspectos menos estudados, como a Educação a Distância, a Educação Superior e a Educação de Jovens e Adultos, o que pode indicar uma tendência importante, indo ao encontro do que a literatura aponta como grandes lacunas para as quais a área deveria voltar-se de forma mais consistente (TOMAINO, 
2009; DALL'ACQUA et al, 2012; MOREIRA, 2012; MOREIRA; DALL'ACQUA; MIRANDA, 2014).

Quanto à categoria temática "Deficiências", percebe-se ser possível desmembrála em três modalidades: intelectual, auditiva e visual. Há também o uso do termo “deficiência” de forma generalizada, não permitindo sua identificação ou especificação.

Há que se destacar que em relação ao período de avaliação anterior, que se encerrou em 2008, houve uma evidente abertura para temáticas ainda não contempladas ou predominantes, estabelecendo-se destaque para "Tecnologia" e "Acessibilidade", "Produção de conhecimento" e "Trabalho no universo das pessoas com deficiências" que emergiram em período mais recente.

No que se refere à "Temática principal" presente nas dissertações e teses e respectivos participantes, os dados analisados possibilitaram a construção do quadro a seguir:

Quadro 4: Ocorrência por Temática, Participantes e Número de dissertações e teses

\begin{tabular}{|c|c|c|}
\hline Temática Principal & Participantes & $\begin{array}{c}\text { Número de } \\
\text { dissertações e teses }\end{array}$ \\
\hline Surdez & $\begin{array}{l}\text { Alunos surdos, professores de } \\
\text { classe comum, professor } \\
\text { especializado, intérprete de } \\
\text { Libras, diretor, pais }\end{array}$ & 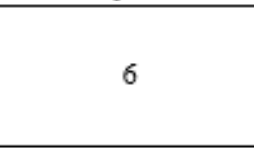 \\
\hline Formação de professores & $\begin{array}{l}\text { Professores de classe comum, } \\
\text { professores especializados, } \\
\text { diretores, coordenadores, } \\
\text { dirigente de ensino, graduandos }\end{array}$ & 4 \\
\hline Deficiência intelectual & $\begin{array}{l}\text { Professores especializados e } \\
\text { alunos com deficiência } \\
\text { intelectual }\end{array}$ & 3 \\
\hline Inclusão escolar & Não se aplica & 2 \\
\hline Sindrome de Down & $\begin{array}{l}\text { Professores do ensino comum, } \\
\text { professor especializado e } \\
\text { familiares }\end{array}$ & 1 \\
\hline Mercado de trabalho & Funcionários com deficiência & 1 \\
\hline $\begin{array}{l}\text { Trajetória escolar e experiência } \\
\text { profissional }\end{array}$ & Professores especializados & 1 \\
\hline Deficiência na educação infantil & $\begin{array}{l}\text { Profissionais da educação } \\
\text { infantil e familiares }\end{array}$ & 1 \\
\hline $\begin{array}{l}\text { Formação de professores em } \\
\text { EaD }\end{array}$ & Coordenadores e professores & 1 \\
\hline Educação de jovens e adultos & $\begin{array}{l}\text { Alunos, familiares, professores } \\
\text { de classe comum e professores } \\
\text { especializados }\end{array}$ & 1 \\
\hline $\begin{array}{l}\text { Acessibilidade na educação } \\
\text { superior }\end{array}$ & Não se aplica & 1 \\
\hline Currículo e educação inclusiva & $\begin{array}{l}\text { Professores do ensino } \\
\text { fundamental e alunos do ensino } \\
\text { médio }\end{array}$ & 1 \\
\hline Salas de recursos multifuncionais & Professores especializados & 1 \\
\hline
\end{tabular}

Fonte: Elaboração própria 
Caracterizando-se por uma gama ampla e diversificada, as informações contidas no Quadro 4 possibilitam apreender com mais precisão as temáticas sobre as quais versou a produção discente no Programa de Pós-graduação em Educação Escolar no que diz respeito à Educação Especial e Educação Inclusiva. Contudo, considerando-se as de maior incidência, "surdez" e "formação de professores" foram as mais recorrentes. Especificamente com relação à "surdez", essa tendência confirma o que outras pesquisas também detectaram sobre o crescente número de estudos que tratam sobre a referida temática. (FREITAS, 2008; ORLANDO; CAIADO, 2014). E cruzando as referidas informações com os dados apresentados anteriormente no Quadro 3 é possível verificar que a "surdez" foi tratada no âmbito da educação de/para surdos, do implante coclear e da questão envolvendo o intérprete de Libras e não exclusivamente a população considerada como recorte do público-alvo da Educação Especial. Já a “formação de professores", aqui desvinculada da formação na modalidade $\mathrm{EaD}$, revela a questão da formação inicial como ainda bastante significativa no âmbito da construção de uma educação inclusiva.

As demais temáticas, um "leque" de possibilidades, quando cotejada com os participantes, permite depreender que novamente o foco principal não ficou restrito ao chamado público alvo, mas envolveu também professores, especializados e não especializados e familiares. Dessa forma, alterando uma tendência presente nas dissertações e teses defendidas no Programa de Pós-graduação em Educação Escolar no período 2002/2008 em que a categoria mais representada foi a de "Alunos" (DALL'ACQUA; ZANIOLO, 2009), no septênio sobre a qual essa investigação versa, a ênfase das pesquisas voltou-se para os participantes "Professores".

Ainda assim cabe destacar que a congruência entre temáticas e palavras-chave se faz de forma incompleta, o que pode estar indicando a necessidade de maior consonância no momento de eleger palavras-chave que melhor retratem ou traduzam a temática sobre a qual versam as pesquisas.

Finalizando, há que se mencionar que a indicação "não se aplica" foi utilizada para referir-se a trabalhos nos quais não houve participantes.

No quadro disposto a seguir são apresentadas informações referentes aos locais em que as pesquisas foram conduzidas. 
Quadro 5: Identificação dos locais onde as pesquisas foram desenvolvidas e números de trabalhos correlatos

\begin{tabular}{|l|c|}
\hline \multicolumn{1}{|c|}{ Locais } & $\begin{array}{c}\text { Número de } \\
\text { Trabalhos }\end{array}$ \\
\hline Banco de Teses da CAPES & 2 \\
\hline Educação de Jovens e Adultos & 1 \\
\hline $\begin{array}{l}\text { Empresa do segundo setor da economia (indústria) que contém } \\
\text { empregados com deficiências }\end{array}$ & 1 \\
\hline Escola de educação infantil e ensino fundamental & 2 \\
\hline Escola municipal & 2 \\
\hline $\begin{array}{l}\text { Escola municipal de ensino fundamental e salas de atendimento } \\
\text { educacional especializado }\end{array}$ & 1 \\
\hline Escola municipal de ensino fundamental II & 1 \\
\hline Escola primária espanhola e escola regular brasileira & 1 \\
\hline Escola regular e instituição especializada & 1 \\
\hline Escolas de educação infantil do Brasil e da Espanha & 1 \\
\hline Escolas estaduais & 2 \\
\hline Escolas regulares de ensino fundamental I e de ensino médio & 1 \\
\hline Não informado & 3 \\
\hline Núcleo pedagógico da diretoria de ensino de rede estadual & 1 \\
\hline Sala de recursos multifuncionais & 1 \\
\hline Universidades públicas & 1 \\
\hline Universidades que possuem cursos na modalidade EaD do Brasil e de & 1 \\
\hline Portugal & 24 \\
\hline Sala de recursos e sala regular & 1 \\
\hline TOTAL & 24 \\
\hline
\end{tabular}

Fonte: Elaboração própria

O que se verifica analisando as informações organizadas no Quadro 5 é que os locais nos quais as pesquisas foram desenvolvidas aparecem "pulverizados" mas que, ainda assim, se forem organizados em conjuntos, é possível constatar que as "Escolas de Ensino Fundamental" foram o lócus prioritário, seguido por "Escolas da Educação Infantil”. Embora em alguns resumos não seja possível identificar se a referência à escola municipal diz respeito a uma Escola de Educação Infantil ou Escola de Ensino Fundamental municipalizada, quando se faz menção à Escola Estadual, sempre será relativa ao Ensino Fundamental II ou mesmo Ensino Médio. Faz-se notar também que trabalhos de investigação que se dedicaram a estudar salas de recursos ou salas de atendimento educacional especializado, o fizeram em paralelo com salas regulares, excetuando uma pesquisa que se dedicou integralmente às salas de recursos multifuncionais.

Outro aspecto interessante diz respeito a pesquisas conduzidas em dois contextos, em particular Brasil/Espanha e Brasil/Portugal, evidenciando uma 
preocupação em ampliar o escopo de análise para realidades que, mesmo se não comparáveis, ainda assim podem contribuir para aprofundar e enriquecer apreciações feitas.

Na sequência são enfocados os tipos de instrumentos e de procedimentos de que se serviram os pesquisadores para realizar suas coletas de dados, bem como a quantidade de trabalhos nos quais eles foram registrados.

Quadro 6: Instrumentos e procedimentos utilizados para coleta de dados em respectivas teses e dissertações

\begin{tabular}{|l|c|}
\hline \multicolumn{1}{|c|}{ Instrumentos e procedimentos para coleta de dados } & Número de Trabalhos \\
\hline Entrevistas & 9 \\
\hline Não especificado & 8 \\
\hline Observações & 7 \\
\hline Questionários & 6 \\
\hline $\begin{array}{l}\text { Análise documental (de materiais didáticos, textos e } \\
\text { atividades elaborados por participantes) }\end{array}$ & 6 \\
\hline Filmagem & 2 \\
\hline Caderno de campo & 1 \\
\hline
\end{tabular}

Fonte: Elaboração própria

Por ordem de ocorrência, verifica-se que "Entrevista" foi o principal instrumento empregado nos trabalhos analisados. Contudo, é preciso que se destaque que, tanto instrumentos como procedimentos múltiplos foram adotados em parte dos estudos investigados. Dessa forma, nem sempre a entrevista constituiu-se na única forma de coleta de dados em uma pesquisa. Seja como for, mesmo que sob a forma de uso combinado, ainda assim as entrevistas foram majoritárias, confirmando uma tendência já verificada em estudos anteriores (BUENO, 2007; 2008; DALL'ACQUA; ZANIOLO, 2009).

É notável também que em oito dos resumos analisados não tenha sido possível identificar tanto instrumentos quanto procedimentos para a realização da coleta de dados, o que pode ser um alerta para que os referidos resumos sejam aprimorados e possam contemplar todas as informações consideradas imprescindíveis.

$\mathrm{Na}$ continuidade dos registros sobre instrumentos e procedimentos percebe-se que as "Observações", seguidas por "Questionários" e "Análise Documental" constituíram-se nas escolhas mais constantes, enquanto que a adoção de "Filmagem" e 
registro em "Caderno de Campo" foram consideradas ocasionais e com menor peso de representatividade.

A seguir são trazidas informações relativas às Abordagens Metodológicas mencionadas nos resumos das dissertações e teses consideradas para o presente estudo.

Tabela 1: Abordagens metodológicas e respectivas porcentagens no conjunto total de trabalhos analisados e subdivididos por mestrado e doutorado

\begin{tabular}{l|c|c|c|c}
\hline $\begin{array}{c}\text { Natureza das } \\
\text { Abordagens } \\
\text { Metodológicas }\end{array}$ & $\begin{array}{c}\text { Número } \\
\text { total de } \\
\text { trabalhos }\end{array}$ & $\begin{array}{c}\text { Porcentagens } \\
\text { de ocorrência } \\
\text { por total (\%) }\end{array}$ & $\begin{array}{c}\text { Porcentagens } \\
\text { para Mestrado } \\
\mathbf{( \% )}\end{array}$ & $\begin{array}{c}\text { Porcentagens } \\
\text { para Doutorado } \\
\mathbf{( \% )}\end{array}$ \\
\hline Qualitativa & 11 & 45,0 & 50,0 & 37,5 \\
\hline Quantitativa & 00 & 0,0 & 0,0 & 0,0 \\
\hline Quanti/Qualitativa & 03 & 12,5 & 12,5 & 12,5 \\
\hline Não informada & 10 & 41,6 & 37,5 & 50,0 \\
\hline Total & $\mathbf{2 4}$ & $\mathbf{1 0 0 , 0}$ & $\mathbf{1 0 0 , 0}$ & $\mathbf{1 0 0 , 0}$ \\
\hline
\end{tabular}

Fonte: Elaboração própria

A grande maioria dos trabalhos refere a adoção de análise de natureza qualitativa, quando confrontada com as demais modalidades, tanto em pesquisas de mestrado quanto de doutorado, referendando assim conclusões obtidas também em outros trabalhos de levantamento e análise de produção (LIMA, 2001; BUENO, 2007; 2014; MANZINI, 2007; DALL'ACQUA; ZANIOLO, 2009).

Finalizando, no quadro a seguir são dispostas informações acerca da ocorrência de citações a referenciais teóricos adotados por mestrandos e doutorandos em suas pesquisas.

Quadro 7: Referenciais teóricos referidos nos resumos de teses e dissertações analisadas

\begin{tabular}{|l|c|}
\hline \multicolumn{1}{|c|}{ Referenciais teóricos/Representantes } & $\begin{array}{c}\text { Número de } \\
\text { trabalhos }\end{array}$ \\
\hline Teoria da Modificabilidade Cognitiva Estrutural (R. Feuerstein) & 2 \\
\hline Perspectiva Ecológica do Desenvolvimento Humano (U. Bronfenbrenner) & 1 \\
\hline Pedagogia Institucional & 1 \\
\hline Teoria Histórico Crítica (L.Vigotski) & 1 \\
\hline Psicanálise (J. Lacan) & 1 \\
\hline Não informado & 18 \\
\hline Total & $\mathbf{2 4}$ \\
\hline
\end{tabular}

Fonte: Elaboração própria 
O Quadro 7 possibilita verificar que, no total, embora seis trabalhos tenham indicado claramente a adoção de um referencial teórico, como ocorre em trabalhos baseados em modelos lógico-dedutivos, essa conduta, no entanto, foi minoritária. As outras $75 \%$ das pesquisas não fizeram alusão a nenhum referencial, o que pode indicar uma lacuna de informação nos resumos. Contudo essa é uma conclusão que não poderia ser feita apenas com base nesta constatação, visto que partir de proposições teóricas fundamentais, visando delas deduzir as análises, não se constitui em um único caminho metodológico. Pesquisa de natureza indutiva, por sua vez, estabelecendo um desenho vetorial contrário, parte da proposição de uma questão à realidade para, posteriormente, estabelecer procedimentos visando assegurar-se de respondê-la, com grau de confiabilidade e validade, visto que se encontra "[...] baseada nos fatos observados, utilizando como ilustração os resultados de trabalhos empíricos referentes [...]". (TREMBLAY, 2010, p. 11). Por outro lado, como bem aponta Bueno (2014):

[...] não se pode confinar as consequências teóricas das investigações somente às pesquisas teóricas, mas ao tratamento que pesquisas de campo recebem e o grau de generalidade que alcançam, especialmente como fruto da relação empiria-teoria estabelecida. (BUENO, 2014, p. 234)

No entanto, ainda tomando em conta as reflexões empreendidas por Bueno (2014) com base na literatura, inclusive internacional, as evidencias parecem demonstrar a pouca importância que a pesquisa teórica tem encontrado na Educação Especial. O pouco valor a essa questão da vertente teórica parece amparar-se em aspectos já apontados por Skrtic (2014) há duas décadas quando, então, alertava para o fato do conhecimento subjacente à área ser de tal forma disseminado a ponto de parecer básico, inerente e desvalorizar-se enquanto referência, como também pela “[...] importância que a Psicologia tem como referência teórica da educação especial, seguida pelas da Pedagogia e da própria educação especial, enquanto que as bases sociais situam-se em segundo plano.” (BUENO, 2014, p. 236). Nessa linha de raciocínio, se os fatos se colocam dessa maneira sem, contudo, fechar conclusões precipitadas, ainda assim considera-se que seja necessário que tal ponto seja levado em consideração por pesquisadores que se dedicam às temáticas tanto da educação especial como da educação inclusiva. 


\section{Considerações finais}

Em síntese, a pesquisa que se destinou a apresentar um panorama da produção discente do Programa de Pós-graduação em Educação Escolar acerca das temáticas Educação Especial e Inclusiva no septênio 2008/2015, revela que algumas tendências detectadas no período 2002/2008 são ainda mantidas. Outras, porém, mostraram-se específicas do momento mais atual.

Em termos de participação no conjunto das dissertações e teses defendidas no referido Programa, tanto a Educação Especial como a Inclusiva mantiveram-se abaixo dos $10 \%$, totalizando, 7,57\% na média, o que pode ser considerado uma porcentagem ainda pequena que, estabilizada ao longo de 14 anos, pode estar indicando uma situação estável. Tal constatação parece refletir, por um lado, que o corpo docente atuando nesse campo de conhecimento permaneceu inalterado, ou ainda, que o referido campo não tem se difundido e sido objeto de estudo por parte de investigadores de outras linhas de pesquisa.

Em relação à Inclusão Escolar ter sido a temática mais investigada e o lócus preferencial ser a "Escola", revela-se que o eixo de interesses deslocou-se de um modelo mais circunscrito e segregado para um outro com características mais abrangentes e contextualizadas.

A vertente qualitativa das pesquisas ainda é predominante, com dados obtidos majoritariamente por meio de entrevistas e com pesquisas de natureza indutiva.

Finalizando, o comentário que merece ser feito a partir dos principais achados desse levantamento da produção discente é que, apesar de uma representatividade mais localizada junto ao corpo de trabalhos oriundos desse Programa de Pós-graduação, mesmo assim, o que se detecta é que tanto a Educação Especial, como mais recentemente a Educação Inclusiva, têm se materializado de forma constante durante uma década e meia. Alinhada com a pesquisa nacional, a produção tem contemplado temáticas emergentes e relevantes, sinalizando na direção não só dos professores, mas também dos alunos identificados como sendo público alvo da Educação Especial que se encontram matriculados em salas regulares, seja do Ensino Fundamental, seja na Educação Infantil.

\section{REFERÊNCIAS}


BUENO, J. G. S. As dissertações sobre a escola: balanço tendencial da produção do PPGEES - 1981/2001. In: MENDES, E. G.; ALMEIDA, M. A.; WILLIAMS, L. C. de A. (Org.). Temas em educação especial: avanços recentes. São Carlos: EDUFSCar, 2004. p. 21-28.

BUENO, J. G. S. A produção discente do PEPG em Educação: História, Política, Sociedade (PUC/SP) no campo dos processos de escolarização, desigualdades sociais e deficiência (2004/2007). In: JESUS, D. M. et al. (Org.) Inclusão, práticas pedagógicas e trajetórias de pesquisa. Porto Alegre: Mediação, 2007. p.199-209.

BUENO, J. G. S. A produção acadêmica sobre inclusão escolar e educação inclusiva. In: MENDES, E. G.; ALMEIDA, M. A.; HAYASHI, M. C. P. I. Temas em educação especial: conhecimentos para fundamentar a prática. Araraquara: Junqueira \& Marin; Brasília: CAPES-PROESP, 2008. p.31-47.

BUENO, J. G. S. A pesquisa brasileira sobre Educação Especial: balanço tendencial das dissertações e teses brasileiras (1987 - 2009). In: BUENO, J. G. S., MUNAKATA, K.; CHIOZZINI, D. F. (Org.). A escola como objeto de estudo - Escola, Desigualdades, Diversidades. Araraquara: Junqueira \& Marin, 2014. p.211-244.

DALL'ACQUA, M. J. C. et al. Evasão e inclusão escolar: convergências e dissonâncias na escolaridade de alunos com deficiências matriculados na Educação de Jovens e Adultos. In: MIGUEL, J. C.; CAMARGO, M. R. R. M. de (Orgs.). A educação de pessoas jovens e adultas em capítulos: contextos, desafios e práticas. São Paulo: PROEX; Cultura Acadêmica, 2012. p.171-182.

DALL'ACQUA, M. J. C.; ZANIOLO, L. O. Tendências de pesquisa em educação especial no programa de pós-graduação em educação escolar da FCL/UNESP. Doxa: Revista Paulista de Psicologia e Educação, Araraquara: UNESP/FCLAR Laboratório Editorial, v.13, p.75-86, 2009.

FERREIRA, J. R.; BUENO, J. G. S. Os 20 anos do GT Educação Especial: gênese, trajetória e consolidação. Revista Brasileira de Educação Especial, Marília, ABPEE, v. 17, p.143-170, 2011.

FREITAS, S. N. Considerações acerca da produção de artigos científicos em educação especial: uma análise da Revista Educação Especial CE/UFSM. In: MENDES, E. G.; ALMEIDA, M. A.; HAYASHI, M. C. P. I. Temas em educação especial: conhecimentos para fundamentar a prática. Araraquara: Junqueira \& Marin; Brasília: CAPES-PROESP, 2008. p.56-72.

GATTI, B.; ANDRÉ, M. A relevância dos métodos de pesquisa qualitativa em Educação no Brasil. In: WELLER, W.; PFAFF, N. Metodologias da pesquisa qualitativa em educação. 3.ed. Petrópolis: Vozes, 2013. p.29-38.

LIMA, P. G. Tendências paradigmáticas na pesquisa educacional. 2001, 302 f. Tese (Doutorado em Educação) - Universidade Estadual de Campinas, Campinas, 2001. 
MANZINI, E. J. et al. Análise de dissertações e teses em educação especial produzidas no Programa de Pós-Graduação em Educação da UNESP - Marília (1993 - 2004).

Revista de Educação Especial, Santa Maria, n. 28, p.341-359, 2006.

MANZINI, J. E. Que tipo de conhecimento as pesquisas de pós-graduação têm fornecido sobre inclusão? In: JESUS, D. M. et al. (Org.). Inclusão, práticas pedagógicas e trajetória de pesquisa. Porto Alegre: Mediação, 2007. p.76-186.

MOREIRA, M. H. B. Educação Especial e Educação: Percepções sobre a formação docente em nível de Pós-Graduação - EaD - no Brasil e em Portugal. 2012, 350 f. Tese (Doutorado em Educação Escolar) - Faculdade de Ciências e Letras, Universidade Estadual Paulista, Araraquara, 2012. Disponível em:

<http://wwws.fclar.unesp.br/agenda-pos/educacao_escolar/2603.pdf>. Acesso em: 14 set. 2015.

MOREIRA, M. H. B.; DALL’ACQUA, M. J. C.; MIRANDA, G. M. L. F. de. Especialização docente em educação especial e EaD: qual a relação estabelecida? In: DALL'ACQUA, M. J. C. (Org.). Tópicos em educação especial e inclusiva: formação, pesquisa, escolarização e famílias. Jundiaí: Paco Editorial, 2014. p.129-156.

NUNES, L. R. O. P.; FERREIRA, J. R.; MENDES, E. G. A produção discente da pósgraduação em educação e psicologia sobre o indivíduo com necessidades educacionais especiais. In: MENDES, E. G.; ALMEIDA, M. A.; WILLIAMS, L. C. de A. (Orgs.). Temas em educação especial: avanços recentes. São Carlos: EDUFSCar, 2004. p.2936.

ORLANDO, R. M.; CAIADO, K. R. M. Educação especial na ANPEd: balanço da produção no GT15 (2000-2012). In: DALL’ACQUA, M. J. C. (Org.). Tópicos em educação especial e inclusiva: formação, pesquisa, escolarização e famílias. Jundiaí: Paco Editorial, 2014. p.109-127.

SKRTIC, T. M. A injustiça institucionalizada: construção e uso da deficiência na escola. In: BUENO, J. G. S.; MUNAKATA, K.; CHIOZZINI, D. F. (Org.). A escola como objeto de estudo: escola, desigualdades e diversidades. Araraquara: Junqueira \& Marin, 2014. p. 173-210.

TOMAINO, G. C. Do ensino especializado à educação de jovens e adultos: análise das trajetórias escolares na perspectiva dos alunos, familiares e professores. 2009, $152 \mathrm{f}$. Dissertação (Mestrado em Educação Escolar) - Faculdade de Ciências e Letras, Universidade Estadual Paulista, Araraquara, 2009. Disponível em: <http://wwws.fclar.unesp.br/agenda-pos/educacao_escolar/1845.pdf>. Acesso em: 14 set. 2015.

TREMBLAY, M. A. Prefácio: Reflexões sobre uma trajetória pessoal da diversidade dos objetos de pesquisa. In: POUPART, J. et al. (Org.). A pesquisa qualitativa: enfoques epistemológicos e metodológicos. Petrópolis: Editora Vozes, 2010. p. 9-30. 


\section{Como referenciar este artigo}

CARNEIRO, Relma Urel Carbone.; DALL'ACQUA, Maria Júlia Canazza.; CARAMORI, Patricia Moralis. Análise sobre temáticas de educação especial e inclusiva no programa de educação escolar da FCL/CAr. Revista on line de Política e Gestão Educacional, Araraquara, v. 22, n. 2, p. 534-553, maio/ago., 2018. ISSN: 15199029. DOI: 10.22633/rpge.v22.n2.maio/ago.2018.11340

Submetido em: 04/02/2018

Revisões Requeridas: 26/04/2018

Aprovado em: 16/05/2018 